Article

\title{
Conjugation with RGD Peptides and Incorporation of Vascular Endothelial Growth Factor Are Equally Efficient for Biofunctionalization of Tissue-Engineered Vascular Grafts
}

\author{
Larisa V. Antonova ${ }^{1}$, Alexander M. Seifalian ${ }^{2,3}$, Anton G. Kutikhin 1,*, \\ Victoria V. Sevostyanova ${ }^{1}$, Vera G. Matveeva ${ }^{1}$, Elena A. Velikanova ${ }^{1}$, \\ Andrey V. Mironov ${ }^{1}$, Amin R. Shabaev ${ }^{4}$, Tatiana V. Glushkova ${ }^{1}$, \\ Evgeniya A. Senokosova ${ }^{1}$, Georgiy Yu. Vasyukov ${ }^{1}$, Evgeniya O. Krivkina ${ }^{1}$, \\ Andrey Yu. Burago ${ }^{1}$, Yuliya A. Kudryavtseva ${ }^{1}$, Olga L. Barbarash ${ }^{1}$ \\ and Leonid S. Barbarash ${ }^{1}$ \\ 1 Research Institute for Complex Issues of Cardiovascular Diseases, Sosnovy Boulevard 6, \\ Kemerovo 650002, Russia; antonova.la@mail.ru (L.V.A.); sevostyanova.victoria@gmail.com (V.V.S.); \\ matveeva_vg@mail.ru (V.G.M.); telella@mail.ru (E.A.V.); a.mir.80@mail.ru (A.V.M.); bio.tvg@mail.ru (T.V.G.); \\ sergeewa.ew@yandex.ru (E.A.S.); v.georgiy@mail.ru (G.Y.V.); leonora92@mail.ru (E.O.K.); \\ keu-73@mail.ru (A.Y.B.); jackie1970@mail.ru (Y.A.K.); olb61@mail.ru (O.L.B.); director@kemcardio.ru (L.S.B.) \\ 2 Centre for Nanotechnology and Regenerative Medicine, UCL Division of Surgery and Interventional \\ Science, University College London, UCL Medical School Building, 21 University Street, \\ London WC1E 6AU, UK; a.seifalian@gmail.com \\ 3 NanoRegMed Ltd., 20-22 Wenlock Road, London N1 7GU, UK \\ 4 Kemerovo Cardiology Dispensary, Sosnovy Boulevard 6, Kemerovo 650002, Russia; reception@kemcardio.ru \\ * Correspondence: antonkutikhin@gmail.com; Tel.: +7-960-907-7067
}

Academic Editor: Shaker A. Mousa

Received: 21 August 2016; Accepted: 31 October 2016; Published: 16 November 2016

\begin{abstract}
The blend of poly(3-hydroxybutyrate-co-3-hydroxyvalerate) (PHBV) and poly( $\varepsilon$-caprolactone) $(\mathrm{PCL})$ has recently been considered promising for vascular tissue engineering. However, it was shown that PHBV/PCL grafts require biofunctionalization to achieve high primary patency rate. Here we compared immobilization of arginine-glycine-aspartic acid (RGD)-containing peptides and the incorporation of vascular endothelial growth factor (VEGF) as two widely established biofunctionalization approaches. Electrospun PHBV/PCL small-diameter grafts with either RGD peptides or VEGF, as well as unmodified grafts were implanted into rat abdominal aortas for 1, 3, 6, and 12 months following histological and immunofluorescence assessment. We detected $\mathrm{CD} 31^{+} / \mathrm{CD} 34^{+} / \mathrm{vWF}^{+}$cells 1 and 3 months postimplantation at the luminal surface of $\mathrm{PHBV} / \mathrm{PCL} / \mathrm{RGD}$ and PHBV/PCL/VEGF, but not in unmodified grafts, with the further observation of $\mathrm{CD} 31^{+} \mathrm{CD} 34^{-} \mathrm{vWF}^{+}$phenotype. These cells were considered as endothelial and produced a collagen-positive layer resembling a basement membrane. Detection of $\mathrm{CD} 31^{+} / \mathrm{CD} 34^{+}$cells at the early stages with subsequent loss of CD34 indicated cell adhesion from the bloodstream. Therefore, either conjugation with RGD peptides or the incorporation of VEGF promoted the formation of a functional endothelial cell layer. Furthermore, both modifications increased primary patency rate three-fold. In conclusion, both of these biofunctionalization approaches can be considered as equally efficient for the modification of tissue-engineered vascular grafts.
\end{abstract}

Keywords: tissue engineering; vascular graft; RGD peptides; vascular endothelial growth factor; endothelialization 


\section{Introduction}

In accordance with the recent statistics, 17.3 million people died of cardiovascular disease (CVD) in 2013 [1], with a trend to increasing incidence at least until 2030 [2]. The vast majority of CVD-related deaths $(>85 \%)$ are due to atherosclerosis [1] leading to ischemic stroke, ischemic heart disease, and peripheral artery disease [3]. Blood vessel replacement and bypass surgery are widely established as appropriate options for the treatment of severe atherosclerosis [4]. Both of them require a vascular conduit; i.e., an autologous great saphenous vein, radial artery, or internal mammary artery [5]. Nevertheless, the use of autografts has certain drawbacks, such as the inconvenience of harvesting and limited availability in patients with severe widespread atherosclerosis or in those who previously underwent bypass surgery [6]. Synthetic vascular grafts made of expanded poly(tetrafluoroethylene), poly(ethylene terephthalate), or polyurethane have been validated as appropriate conduits for medium and large caliber $(>6 \mathrm{~mm})$ arteries [5,7]. However, their performance in small caliber $(\leq 6 \mathrm{~mm})$ arteries are generally poor, with a patency rate of only $25 \%$ at 3 years postimplantation [5]. The reasons for this include intimal hyperplasia and thrombosis secondary to a low blood flow, lack of endothelialization, high shear, and compliance mismatch $[7,8]$.

Vascular tissue engineering is considered as a promising approach for producing biocompatible and mechanically competent small caliber vascular substitutes [9]. Many types of natural and synthetic biodegradable polymers have been investigated and used to prepare tubular grafts for in situ vascular tissue engineering [7]. Natural polymers display excellent biocompatibility and biodegradability with non-toxic end products; however, they are highly immunogenic, have poor processability, and their mechanical properties are commonly insufficient for artificial vascular grafts $[7,10,11]$. On the other hand, synthetic polymers usually have low immunogenicity, excellent mechanical properties, and processability, but lack biocompatibility (e.g., cell recognition sites) [7]. To overcome these problems, we applied polymer blending, a widely established approach, to prepare a desirable bio-composite for the tissue-engineered vascular graft $[5,7,10]$.

For the blending, we selected poly(E-caprolactone) (PCL) and poly(3-hydroxybutyrate-co-3hydroxyvalerate) (PHBV). PCL is a semi-crystalline aliphatic polyester synthesized via ring-opening polymerization of $\varepsilon$-caprolactone [7]. PCL is well known for its unique mechanical properties [11,12], slow biodegradation, low immunogenicity, and good drug permeability [7]. However, PCL has poor cell affinity due to its high hydrophobicity and lack of cell-binding signals; this significantly hinders endothelialization of the luminal surface [7]. PHBV is a highly crystalline aliphatic polyester produced by microorganisms as a storage compound [13]. As a natural biomaterial, it has no residual impurities, catalysts, or initiators [12], and possesses slow biodegradability [14] and high cytocompatibility [15]. Hence, we hypothesized that a blend of PHBV with PCL would be efficient for vascular tissue engineering purposes. In our initial in vivo study, a quarter of electrospun small-diameter PHBV/PCL grafts demonstrated spontaneous endothelialization in a rat abdominal aorta replacement model [16]; however, a primary patency rate of $25 \%$ was not considered to be sufficiently high for starting a preclinical trial on large animals.

A number of strategies have been implemented to endow the luminal surface of vascular grafts with the ability to adhere endothelial cells [7]. Most of them involve immobilizing cell adhesive proteins or bioactive peptides on the surface to enhance endothelial cell adhesion following rapid endothelialization [7]. In comparison with proteins, bioactive peptides have high stability and simple structure [7]. Furthermore, bioactive peptides can be immobilized onto material surfaces by either physical absorption or chemical reactions [7]. Incorporation of growth factors into polymer scaffolds during electrospinning is another popular strategy to promote cell adhesion and infiltration of the vascular grafts $[7,10,11,17]$. 
Therefore, we attempted to functionalize our grafts with either arginine-glycine-aspartic acid (RGD)-containing peptides or vascular endothelial growth factor (VEGF), both being widely established targets in vascular tissue engineering [7]. RGD is a tripeptide sequence widely distributed within extracellular matrix proteins (e.g., laminin, fibronectin, and von Willebrand factor/vWF) [18]. RGD is recognized as a ligand by integrins, receptors crucially important for cell adhesion, proliferation, survival, migration, and differentiation [19]. Hence, RGD peptides were proposed as a potential agent for improving polymer biocompatibility-particularly adhesive properties. Among the variety of available growth factors, we selected VEGF, the most powerful growth factor in the promotion of angiogenesis and vasculogenesis [20,21]. In addition to a plethora of other effects, VEGF induces the proliferation, survival, migration, and differentiation of endothelial cells $[11,20,21]$.

The following studies by our group demonstrated that either conjugation with RGD peptides or the incorporation of VEGF improves biocompatibility, physico-mechanical properties, and enhances endothelialization of electrospun PHBV/PCL vascular grafts [22,23]. However, in vivo comparative assessment of the mentioned modifications in either short- or long-term periods is still lacking. Here we performed the implantation of unmodified grafts and grafts either conjugated with RGD peptides or with incorporated VEGF into rat abdominal aorta following histological and immunohistochemical examination at ascending time points.

\section{Results}

We first implanted RGD-, VEGF-, or non-treated PHBV/PCL grafts into abdominal aortas of Wistar rats (Figure 1). Rats were sacrificed 1, 3, 6, and 12 months postimplantation, and grafts were then collected for analysis.
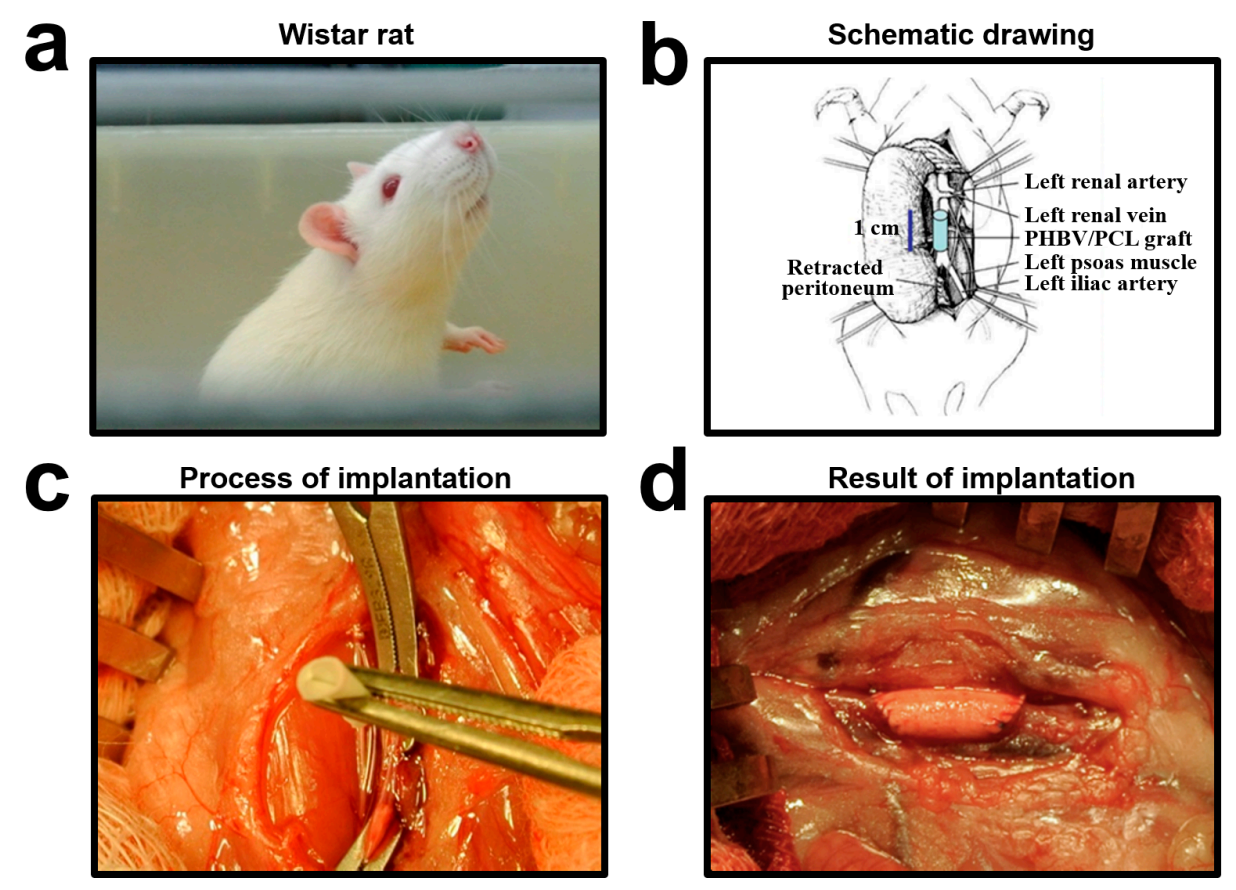

Figure 1. Implantation of the vascular grafts. (a) Wistar rat used for implantation; (b) schematic drawing of the surgery; (c) the process of implantation-aorta is temporarily clamped proximally and distally; (d) implanted graft, the anterior abdominal wall before the closure. PCL: poly( $\varepsilon$-caprolactone); PHBV: poly(3-hydroxybutyrate-co-3-hydroxyvalerate). 
It has been shown that transanastomosal ingrowth of cells is significantly more abundant in rats compared to human vasculature [24]. To avoid this bias, we assessed only midgraft area, and not anastomoses. Having performed histological examination of hematoxylin and eosin ( $\mathrm{H} \& \mathrm{E})$-stained grafts, we observed a thrombotic occlusion within 75\% (3/4) of unmodified PHBV/PCL grafts at all time points (Figure 2a). On the contrary, 75\% (3/4) of the grafts modified with either RGD peptides (Figure $2 b$ ) or VEGF (Figure 2c) showed primary patency.

Further, we performed a double immunostaining using well-recognized endothelial cell markers CD31 and CD34 [25,26] to assess endothelialization of the implanted grafts. Occluded unmodified grafts demonstrated aggregates of disorganized cells not characteristic of normalized vasculature (Figure 3a). In contrast, patent RGD- and VEGF-modified grafts showed CD31 ${ }^{+} / \mathrm{CD} 34^{+}$ cells at the luminal surface 1 and 3 months postimplantation, and CD31 $1^{+} / \mathrm{CD} 34^{-}$cells 6 and 12 months postimplantation (Figure 3b,c). Strikingly, starting from month 3 of the experiment, cells at the luminal surface of patent grafts modified with either RGD peptides or VEGF exhibited an elongated phenotype characteristic of endothelial cells (Figure S1, bottom insert represents a positive control). When we compared two types of the modified grafts, differences in the number of $\mathrm{CD} 31^{+}$cells became insignificant in the sixth month; in addition, there were no differences in the number of $\mathrm{CD} 34^{+}$cells at all time points (Figure 3d).

As an alternative marker of endothelial cells, we additionally stained grafts for the extracellular matrix protein von Willebrand factor (vWF), which establishes contacts between collagens, laminins, and endothelial cells [27]. We detected a layer of $\mathrm{vWF}^{+}$cells at the luminal surface of patent grafts with either conjugated RGD peptides or incorporated VEGF, but not in occluded control grafts at all time points (Figure $4 \mathrm{a}-\mathrm{c}$ ). Differences in the number of $\mathrm{vWF}^{+}$cells between two types of modified grafts became significant only to month 12 (Figure $4 \mathrm{~d}$ ). These results indicated the formation of an endothelial cell layer and improved endothelialization of RGD- and VEGF-treated grafts.

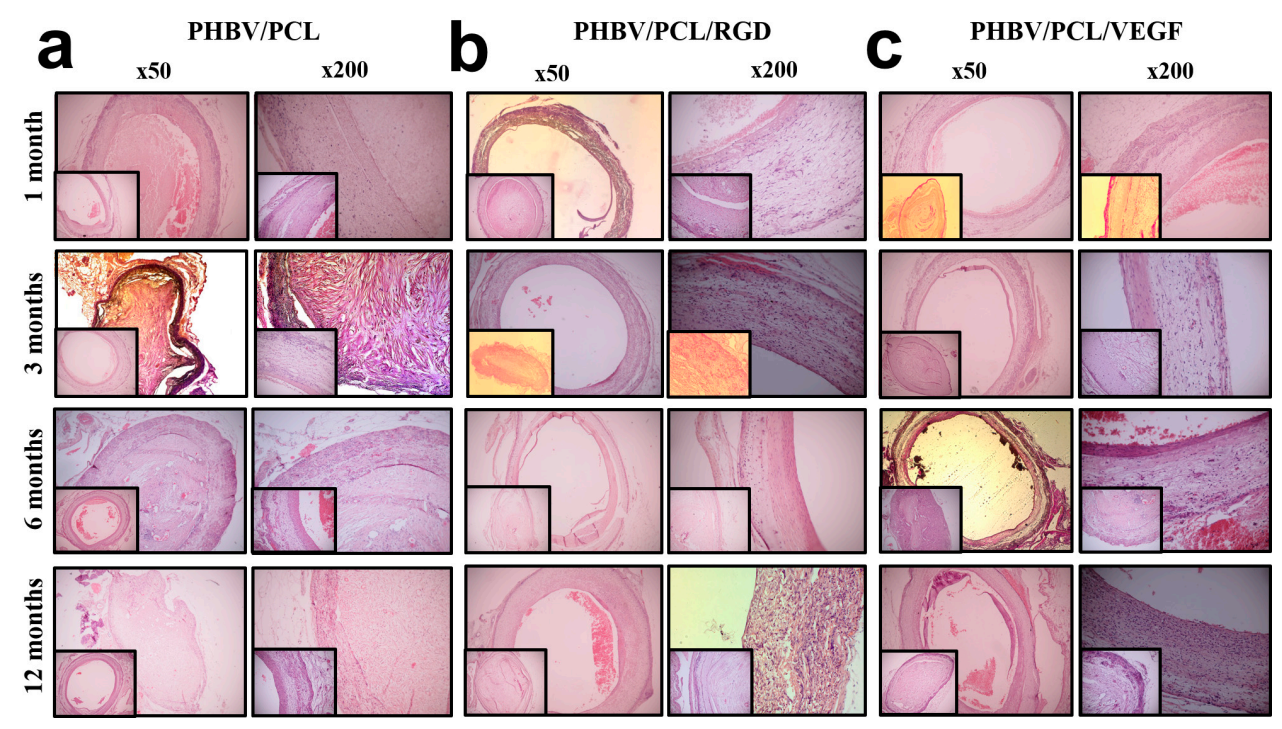

Figure 2. Hematoxylin and eosin ( $\mathrm{H} \& \mathrm{E})$ staining of the unmodified grafts and grafts with either conjugated arginine-glycine-aspartic acid (RGD) peptides or incorporated vascular endothelial growth factor (VEGF) at 1,3,6, and 12 months postimplantation; magnification: $50 \times$ and $200 \times$. Representative images of: (a) poly(3-hydroxybutyrate-co-3-hydroxyvalerate)/poly( $\varepsilon$-caprolactone) (PHBV/PCL) grafts; (b) PHBV/PCL/RGD grafts; (c) PHBV/PCL/VEGF grafts. Images of corresponding patent PHBV/PCL along with occluded PHBV/PCL/RGD and PHBV/PCL/VEGF grafts are presented as bottom inserts. 


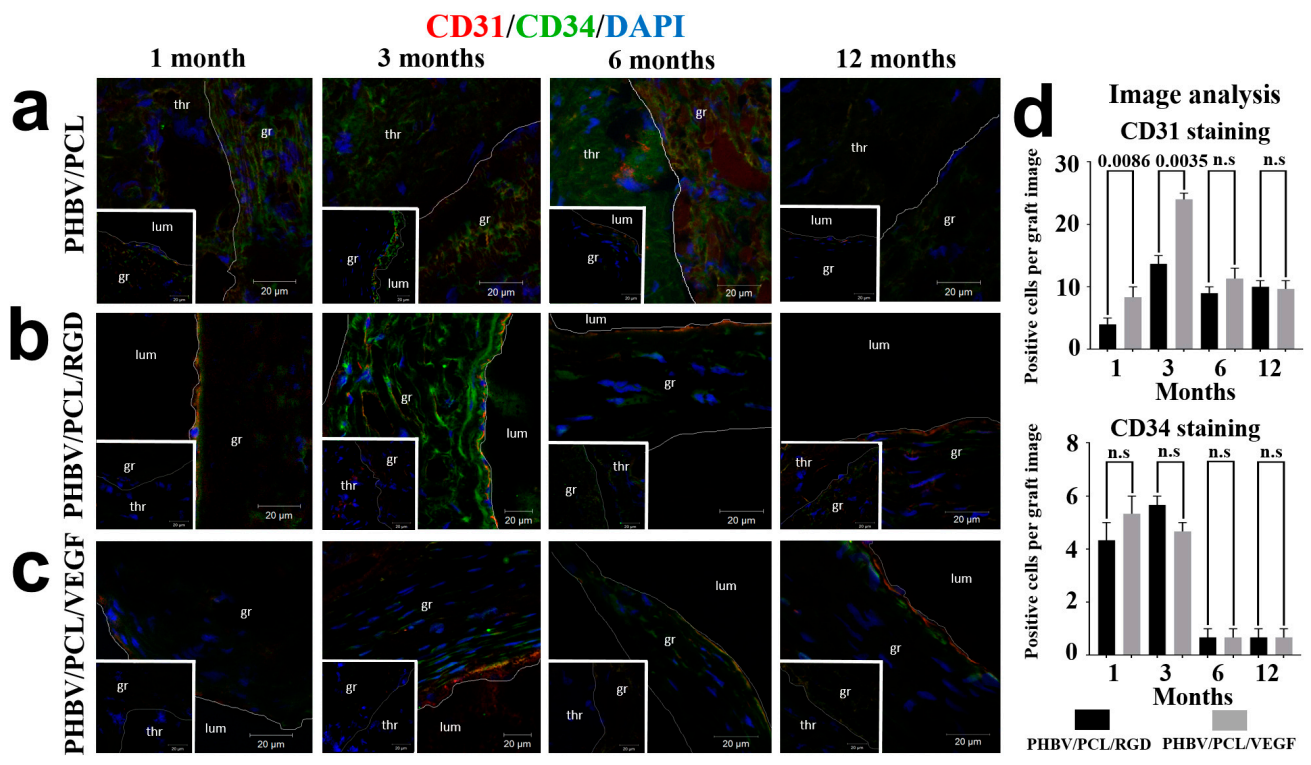

Figure 3. Combined CD31 (red), CD34 (green), and 4',6-diamidino-2-phenylindole (DAPI, blue) staining. Representative images of: (a) PHBV/PCL grafts; (b) PHBV/PCL/RGD grafts; (c) PHBV/PCL/VEGF grafts. Thr is for thrombus, gr is for graft, lum is for lumen. Images of corresponding patent PHBV/PCL along with occluded PHBV/PCL/RGD and PHBV/PCL/VEGF grafts are presented as bottom inserts; (d) Quantitative image analysis, data are represented as mean with range, $p$-values are reported in a numerical manner, n.s. is for not significant, two-tailed Student's $t$-test. Non-modified PHBV/PCL grafts were not included into analysis, since they were devoid of $\mathrm{CD} 31^{+}$and $\mathrm{CD} 34^{+}$cells.

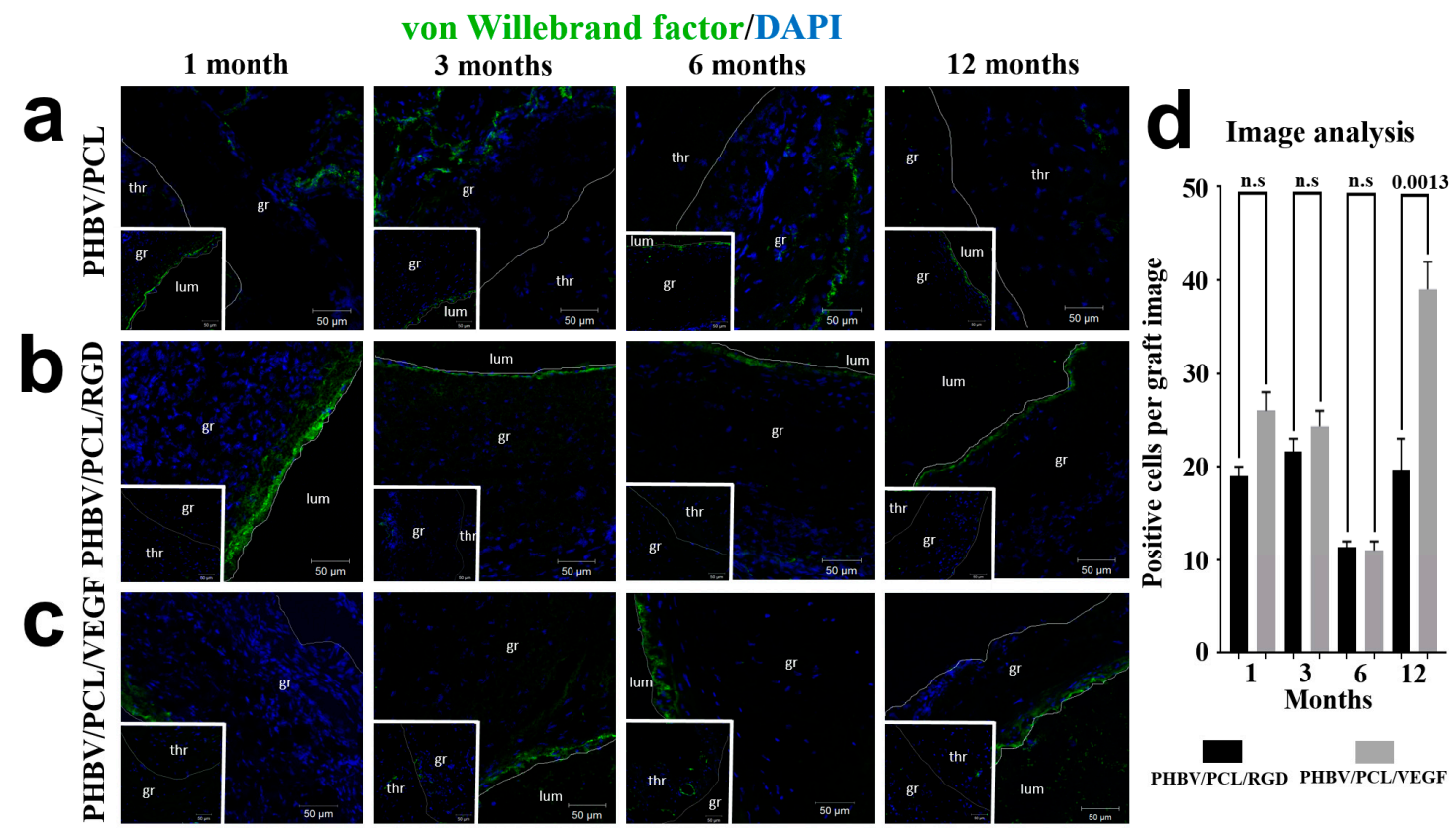

Figure 4. Combined von Willebrand factor (vWF, green) and DAPI (blue) staining. Representative images of: (a) PHBV/PCL grafts; (b) PHBV/PCL/RGD grafts; (c) PHBV/PCL/VEGF grafts. Thr is for thrombus, gr is for graft, lum is for lumen. Images of corresponding patent PHBV/PCL along with occluded PHBV/PCL/RGD and PHBV/PCL/VEGF grafts are presented as bottom inserts; (d) Quantitative image analysis, data are represented as mean with range, $p$-values are reported numerically, n.s. is for not significant, two-tailed Student's $t$-test. Non-modified PHBV/PCL grafts were not included in the analysis, since their luminal surface was devoid of $\mathrm{vWF}^{+}$cells, while the single positive cells within the graft wall were irrelevant for the assessment of endothelialization. 
Development of the basement membrane requires deposition of collagen chains I and IV [28]. To ask whether the observed endothelial cells are able to produce collagen for basement membrane development, we performed a double immunostaining for collagens I and IV. As expected, combined collagen I/IV staining identified a collagen-positive layer underneath the luminal surface of the patent grafts with either conjugated RGD peptides or incorporated VEGF at all the time points, but not in occluded unmodified grafts (Figure $5 \mathrm{a}-\mathrm{c}$ ). Differences in the number of collagen I/IV ${ }^{+}$cells were ambiguous at distinct time points (Figure $5 \mathrm{~d}$ ). These data suggest the formation of basement membrane by endothelial cells upon RGD or VEGF treatment.

Of particular importance is that patent non-modified graft contained CD $31^{+} / \mathrm{CD} 34^{+}$cells, a layer of $\mathrm{vWF}^{+}$cells, and collagen IV (Figure 2a, Figure 3a, Figure 4a, and Figure 5a, bottom inserts). In contrast, non-patent RGD/VEGF-modified grafts were devoid of CD31, CD34, or vWF-positive cells, having aggregates of disorganized cells instead (Figure 2b,c; Figure 3b,c; Figure 4b,c; and Figure 5b,c; bottom inserts), as in occluded unmodified grafts.

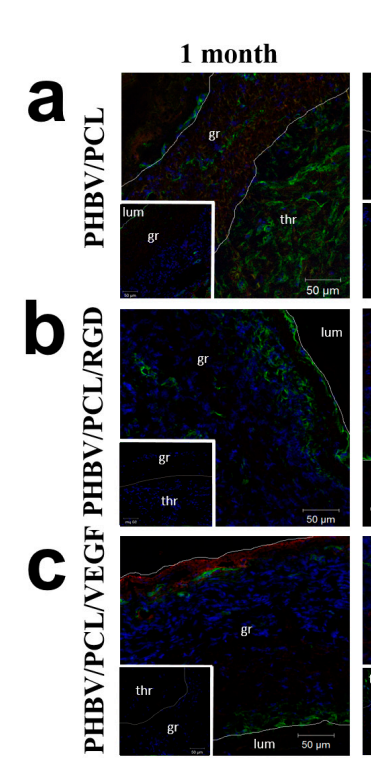

\section{Collagen I/Collagen IV/DAPI}
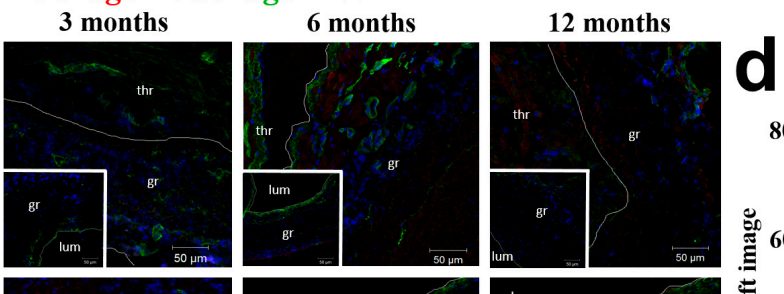

Image analysis
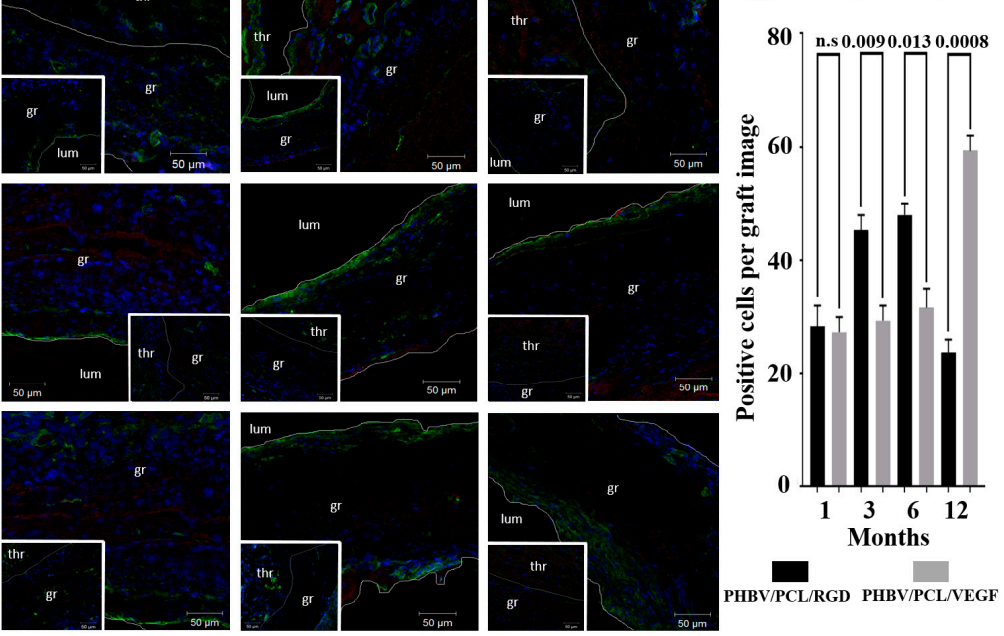

Figure 5. Combined collagen I (red), collagen IV (green), and DAPI (blue) staining. Representative images of: (a) PHBV / PCL grafts; (b) PHBV/PCL/RGD grafts; (c) PHBV/PCL/VEGF grafts. Thr is for thrombus, gr is for graft, lum is for lumen. Images of corresponding patent PHBV/PCL along with occluded PHBV/PCL/RGD and PHBV/PCL/VEGF grafts are presented as bottom inserts; (d) Quantitative image analysis, data are represented as mean with range, $p$-values are reported numerically, n.s. is for not significant, two-tailed Student's $t$-test. Non-modified PHBV/PCL grafts were not included in the analysis, since their luminal surface was devoid of collagen $\mathrm{I}^{+}$or collagen $\mathrm{IV}^{+}$cells, while the single positive cells within the graft wall were irrelevant for the assessment of endothelialization.

\section{Discussion}

We previously found that either conjugation with RGD peptides or incorporation of VEGF improve biophysical properties of electrospun PHBV/PCL small-diameter vascular grafts [22,23]. Modification with VEGF reduced mean pore area and mean fiber diameter in comparison with modification with RGD peptides [22,23]. Grafts with incorporated VEGF consisted mostly of nanofibers; on the contrary, those with RGD were formed mostly of microfibers [22,23]. As known, nanofibers enhance endothelial cell proliferation and adhesion as opposed to fibers with a larger diameter [29-31]; moreover, incorporation of VEGF allowed fabrication of the scaffolds with micro- to nanoscale topography similar to the natural extracellular matrix (ECM) [11,32,33]. Likewise, stress-strain curve, elasticity, and stiffness of the grafts modified with VEGF were closer to internal mammary artery in 
comparison with the RGD-modified grafts [22,23]. However, to the best of our knowledge, no studies compared in vivo efficiency of conjugation with RGD peptides and incorporation of VEGF in the same setting.

Here we conducted in vivo short- and long-term testing of electrospun PHBV/PCL small-diameter vascular grafts, including those with either conjugated RGD peptides or incorporated VEGF. Both of these biofunctionalization approaches improved endothelialization, promoted collagen production, and increased either short- or long-term primary patency three-fold compared to non-treated grafts. As a quarter of unmodified grafts were patent, we suggested that the PHBV/PCL blend itself is able to cause spontaneous endothelialization that can be significantly enhanced by either conjugation with RGD peptides or incorporation of VEGF. However, both non-modified and RGD/VEGF-modified grafts fail to develop features of a native vessel when early thrombosis occurs, possibly due to the lack of cell migration and perfusion.

Either RGD peptides or VEGF recruited $\mathrm{CD} 31^{+} / \mathrm{CD} 34^{+} / \mathrm{vWF}^{+}$(i.e., "transitional" endothelial cells to the luminal surface) 1 and 3 months postimplantation, with further differentiation to $\mathrm{CD}^{+} 1^{+} / \mathrm{CD} 34^{-} / \mathrm{vWF}^{+}$(i.e., mature endothelial cells) 6 and 12 months postimplantation. Both RGD peptide conjugation and VEGF incorporation resulted in the development of the $\mathrm{vWF}^{+}$layer at all time points. Furthermore, endothelial cells synthesized collagen IV, forming a layer beneath the luminal surface that resembled a basement membrane. This can explain the increase in primary patency rate, since rapid endothelialization is well recognized as a key factor contributing to long-term patency $[7,8]$. However, neither visual examination nor quantitative image analysis identified differences in endothelialization pattern or patency between the grafts modified with either RGD peptides or VEGF. Despite enhanced biophysical properties provided by the incorporation of VEGF [22,23], we therefore considered these approaches as equally efficient.

The use of either RGD peptides or VEGF to enhance the biocompatibility of polymers is not novel [34]. However, to the best of our knowledge, nobody has compared these two biofunctionalization approaches in the same setting (e.g., in a rat abdominal aorta replacement model). A limitation of our study is a low number of animals $(n=4)$ per each time point; nevertheless, we included four time points per graft type to better characterize the evolution of cellularity over time, which is one of the most interesting results of our approach. Another shortcoming, related to the rat model, is that transanastomosal ingrowth of cells is excessive in rats in comparison with humans [24]; thus, we assessed only midgraft areas. Detection of $\mathrm{CD} 31^{+} / \mathrm{CD} 34^{+}$cells 1 and 3 months postimplantation with further change in phenotype to $\mathrm{CD} 31^{+} \mathrm{CD} 34^{-}$also points to the cell adhesion from the bloodstream, but not on migration from anastomoses.

We further plan to use a senescent sheep model for the evaluation of the small-diameter PHBV / PCL vascular grafts modified with either bioactive peptides or growth factors. The anatomic and hemodynamic conditions, as well as blood coagulation are similar to the human vasculature, while the long neck without any bifurcation provides easy access to the common carotid artery, which is a common site for implantation of 4-6 mm diameter vascular constructs [35-37]. Moreover, sheep represent a "worst-case model" due to the propensity for accelerated vascular calcification, allowing the assessment of the degenerative processes in a relatively short time period [37].

\section{Materials and Methods}

\subsection{Graft Preparation}

Electrospun vascular grafts were manufactured from PHBV/PCL (1:2, Sigma-Aldrich, St. Louis, $\mathrm{MO}, \mathrm{USA}$ )/ chloroform solution with and without VEGF, as in [23].

\subsection{Polymer Amination-Activation}

Grafts were processed as in $[38,39]$ following air drying. 


\subsection{RGD Peptide Conjugation}

Linker solution was prepared as in [40]. The synthesis of the RGD-containing biomolecule was performed as in [41]. Incubation in the linker solution and following treatment with the RGD solution $(0.2 \mathrm{mg} / \mathrm{mL})$ was carried out as in [22,39].

\subsection{In Vivo Implantation}

For the animal experiments, we used Wistar rats (male, 6-month-old, 400-450 g body weight, $n=48$ ). The ethical committee of Research Institute for Complex Issues of Cardiovascular Diseases approved the study protocol (project No. 14-25-00050, 18 September 2014). Ethylene oxide-sterilized $10 \mathrm{~mm}$ length and $2 \mathrm{~mm}$ diameter PHBV/PCL, PHBV/PCL/RGD, and PHBV/PCL/VEGF ( $n=16$ per group) grafts were placed into abdominal aorta. Animal handling and surgery were performed as in [23]. One-fourth $(n=4)$ of rats in each of the groups was sacrificed 1, 3, 6, and 12 months postimplantation by an intraperitoneal injection of a sodium pentobarbital ( $100 \mathrm{mg} / \mathrm{kg}$ body weight).

Equal parts of the explanted grafts and residual aortic tissue were either frozen at $-140{ }^{\circ} \mathrm{C}$ or fixed in $10 \%$ formalin, as in [23].

\subsection{Histological Examination}

After being fixed with formalin, grafts were embedded in paraffin, further stained with hematoxylin and eosin, and finally examined by light microscopy (Axio Imager A1, Carl Zeiss, Cohen, Germany), as in [23].

\subsection{Immunofluorescence Examination}

Snap-frozen tissue samples were sectioned, treated, and stained as in [23], with additional staining by unconjugated mouse anti-collagen I (ab6308, Abcam, Cambridge, MA, USA) and rabbit anti-collagen IV (ab6586, Abcam). Native rat aorta and bovine serum albumin solution were used as a positive (Figure S2a) and negative (Figure S2b) control, respectively. Slides were examined by confocal laser scanning microscopy using LSM 700 (Carl Zeiss), as in [23]. Quantitative image analysis was conducted utilizing ImageJ software (National Institutes of Health, Bethesda, MD, USA). For the correct quantification, we first normalized each signal individually to the corresponding DAPI (4',6-diamidino-2-phenylindole) signal of each vision field. Furthermore, we manually counted the number of positive cells in each vision field (three vision fields per staining; four stainings per time point) following quantitative image analysis for all the time points.

\subsection{Scanning Electron Microscopy}

Segments of explanted grafts ( $n=4$ per time point) were fixed with $2.5 \%$ glutaraldehyde (Sigma-Aldrich) during $24 \mathrm{~h}$ and then postfixed with 1\% osmium tetroxide (Serva Electrophoresis) during $2 \mathrm{~h}$ at room temperature following dehydration in a graded ethanol series (from 30\% to $100 \%$ ) and further drying at $37{ }^{\circ} \mathrm{C}$. Visualization was performed on a scanning electron microscope (Hitachi S-3400N, Hitachi, Chiyoda, Tokyo, Japan) in a low vacuum mode at $30 \mathrm{kV}$ accelerating voltage, without any coating. Native rat aorta was used as a positive control.

\subsection{Statistical Analysis}

Statistical analysis was carried out utilizing GraphPad Prism (GraphPad Software). A sampling distribution was evaluated by Kolmogorov-Smirnov test and a D'Agostino-Pearson test. Descriptive data were represented by the mean with range. Two-tailed Student's $t$-test was applied to compare independent groups, with further adjustment for multiple comparisons using Tukey's post hoc test if needed. $p$-values $\leq 0.05$ were defined as significant. 
Supplementary Materials: Supplementary materials can be found at www.mdpi.com/1422-0067/17/11/1920/s1.

Acknowledgments: This investigation was performed in the Research Institute for Complex Issues of Cardiovascular Diseases owing to the funding of Russian Science Foundation (project No. 14-25-00050).

Author Contributions: Larisa V. Antonova, Alexander M. Seifalian, Anton G. Kutikhin, Victoria V. Sevostyanova, Yuliya A. Kudryavtseva, Olga L. Barbarash, and Leonid S. Barbarash conceived and designed the study; Victoria V. Sevostyanova, Evgeniya A. Senokosova, and Evgeniya O. Krivkina fabricated the grafts and conducted VEGF incorporation; Alexander M. Seifalian performed the modification with RGD peptides; Andrey V. Mironov, Amin R. Shabaev, Elena A. Velikanova, Evgeniya A. Senokosova, and Evgeniya O. Krivkina performed in vivo implantation; Tatiana V. Glushkova conducted scanning electron microscopy; Andrey Yu. Burago carried out histological examination; Vera G. Matveeva, Elena A. Velikanova, Evgeniya A. Senokosova, and Georgiy Yu. Vasyukov performed immunofluorescence examination; Anton G. Kutikhin carried out quantitative image and statistical analysis; Larisa V. Antonova, Victoria V. Sevostyanova, and Anton G. Kutikhin wrote the manuscript.

Conflicts of Interest: The authors declare no conflict of interest.

\section{References}

1. GBD 2013 Mortality and Causes of Death Collaborators. Global, regional, and national age-sex specific all-cause and cause-specific mortality for 240 causes of death, 1990-2013: A systematic analysis for the Global Burden of Disease Study 2013. Lancet 2015, 385, 117-171.

2. Mathers, C.D.; Loncar, D. Projections of global mortality and burden of disease from 2002 to 2030. PLoS Med. 2006, 3, e442. [CrossRef] [PubMed]

3. Bentzon, J.F.; Otsuka, F.; Virmani, R.; Falk, E. Mechanisms of plaque formation and rupture. Circ. Res. 2014, 114, 1852-1866. [CrossRef] [PubMed]

4. Benrashid, E.; McCoy, C.C.; Youngwirth, L.M.; Kim, J.; Manson, R.J.; Otto, J.C.; Lawson, J.H. Tissue engineered vascular grafts: Origins, development, and current strategies for clinical application. Methods 2016, 99, 131-139. [CrossRef] [PubMed]

5. Rocco, K.A.; Maxfield, M.W.; Best, C.A.; Dean, E.W.; Breuer, C.K. In vivo applications of electrospun tissue-engineered vascular grafts: A review. Tissue Eng. Part B Rev. 2014, 20, 628-640. [CrossRef] [PubMed]

6. Tara, S.; Rocco, K.A.; Hibino, N.; Sugiura, T.; Kurobe, H.; Breuer, C.K.; Shinoka, T. Vessel bioengineering. Circ. J. 2014, 78, 121-129. [CrossRef]

7. Ren, X.; Feng, Y.; Guo, J.; Wang, H.; Li, Q.; Yang, J.; Hao, X.; Lv, J.; Ma, N.; Li, W. Surface modification and endothelialization of biomaterials as potential scaffolds for vascular tissue engineering applications. Chem. Soc. Rev. 2015, 44, 5680-5742. [CrossRef] [PubMed]

8. Chong, D.S.; Lindsey, B.; Dalby, M.J.; Gadegaard, N.; Seifalian, A.M.; Hamilton, G. Luminal surface engineering, "micro and nanopatterning": Potential for self endothelialising vascular grafts? Eur. J. Vasc. Endovasc. Surg. 2014, 47, 566-576. [CrossRef] [PubMed]

9. Palumbo, V.D.; Bruno, A.; Tomasello, G.; Damiano, G.; Lo Monte, A.I. Bioengineered vascular scaffolds: The state of the art. Int. J. Artif. Organs 2014, 37, 503-512. [CrossRef] [PubMed]

10. Sankaran, K.K.; Subramanian, A.; Krishnan, U.M.; Sethuraman, S. Nanoarchitecture of scaffolds and endothelial cells in engineering small diameter vascular grafts. Biotechnol. J. 2015, 10, 96-108. [CrossRef] [PubMed]

11. Ingavle, G.C.; Leach, J.K. Advancements in electrospinning of polymeric nanofibrous scaffolds for tissue engineering. Tissue Eng. Part B Rev. 2014, 20, 277-293. [CrossRef] [PubMed]

12. Naito, Y.; Rocco, K.; Kurobe, H.; Maxfield, M.; Breuer, C.; Shinoka, T. Tissue engineering in the vasculature. Anat. Rec. 2014, 297, 83-97. [CrossRef] [PubMed]

13. Quillaguamán, J.; Guzmán, H.; van-Thuoc, D.; Hatti-Kaul, R. Synthesis and production of polyhydroxyalkanoates by halophiles: Current potential and future prospects. Appl. Microbiol. Biotechnol. 2010, 85, 1687-1696. [CrossRef] [PubMed]

14. Giavaresi, G.; Tschon, M.; Borsari, V.; Daly, J.H.; Liggat, J.J.; Fini, M.; Bonazzi, V.; Nicolini, A.; Carpi, A.; Morra, M.; et al. New polymers for drug delivery systems in orthopaedics: In vivo biocompatibility evaluation. Biomed. Pharmacother. 2004, 58, 411-417. [CrossRef]

15. Chen, G.Q.; $\mathrm{Wu}, \mathrm{Q}$. The application of polyhydroxyalkanoates as tissue engineering materials. Biomaterials 2005, 26, 6565-6578. [CrossRef] [PubMed] 
16. Antonova, L.V.; Mukhamadiyarov, R.A.; Mironov, A.V.; Burago, A.Y.; Velikanova, E.A.; Sidorova, O.D.; Kudryavtseva, Y.A.; Barbarash, O.L.; Barbarash, L.S. A morphological investigation of the polyhydroxybutyrate/valerate and polycaprolactone biodegradable small-diameter vascular graft biocompatibility. Genes Cells 2015, 10, 71-77.

17. Woods, I.; Flanagan, T.C. Electrospinning of biomimetic scaffolds for tissue-engineered vascular grafts: Threading the path. Expert Rev. Cardiovasc. Ther. 2014, 12, 815-832. [CrossRef] [PubMed]

18. Wang, F.; Li, Y.; Shen, Y.; Wang, A.; Wang, S.; Xie, T. The functions and applications of RGD in tumor therapy and tissue engineering. Int. J. Mol. Sci. 2013, 14, 13447-13462. [CrossRef] [PubMed]

19. Harburger, D.S.; Calderwood, D.A. Integrin signalling at a glance. J. Cell Sci. 2009, 122, 159-163. [CrossRef] [PubMed]

20. Azimi-Nezhad, M. Vascular endothelial growth factor from embryonic status to cardiovascular pathology. Rep. Biochem. Mol. Biol. 2014, 2, 59-69. [PubMed]

21. Thanigaimani, S.; Kichenadasse, G.; Mangoni, A.A. The emerging role of vascular endothelial growth factor (VEGF) in vascular homeostasis: Lessons from recent trials with anti-VEGF drugs. Curr. Vasc. Pharmacol. 2011, 9, 358-380. [CrossRef] [PubMed]

22. Antonova, L.V.; Seifalian, A.M.; Kutikhin, A.G.; Sevostyanova, V.V.; Krivkina, E.O.; Mironov, A.V.; Burago, A.Y.; Velikanova, E.A.; Matveeva, V.G.; Glushkova, T.V.; et al. Bioabsorbable bypass grafts biofunctionalised with RGD have enhanced biophysical properties and endothelialisation tested in vivo. Front. Pharmacol. 2016, 7, 136. [CrossRef] [PubMed]

23. Antonova, L.V.; Sevostyanova, V.V.; Kutikhin, A.G.; Mironov, A.V.; Krivkina, E.O.; Shabaev, A.R.; Matveeva, V.G.; Velikanova, E.A.; Sergeeva, E.A.; Burago, A.Y.; et al. Vascular endothelial growth factor improves physico-mechanical properties and enhances endothelialization of poly(3-hydroxybutyrate-co-3hydroxyvalerate)/poly(E-caprolactone) small-diameter vascular grafts in vivo. Front. Pharmacol. 2016, 7, 230. [CrossRef] [PubMed]

24. Talacua, H.; Smits, A.I.; Muylaert, D.E.; van Rijswijk, J.W.; Vink, A.; Verhaar, M.C.; Driessen-Mol, A.; van Herwerden, L.A.; Bouten, C.V.; Kluin, J.; et al. In situ tissue engineering of functional small-diameter blood vessels by host circulating cells only. Tissue Eng. Part A 2015, 21, 2583-2594. [CrossRef] [PubMed]

25. Hristov, M.; Erl, W.; Weber, P.C. Endothelial progenitor cells: Mobilization, differentiation, and homing. Arterioscler. Thromb. Vasc. Biol. 2003, 23, 1185-1189. [CrossRef] [PubMed]

26. Suzuki, Y.; Yamamoto, K.; Ando, J.; Matsumoto, K.; Matsuda, T. Arterial shear stress augments the differentiation of endothelial progenitor cells adhered to VEGF-bound surfaces. Biochem. Biophys. Res. Commun. 2012, 423, 91-97. [CrossRef] [PubMed]

27. Inoue, O.; Suzuki-Inoue, K.; Ozaki, Y. Redundant mechanism of platelet adhesion to laminin and collagen under flow: Involvement of von Willebrand factor and glycoprotein Ib-IX-V. J. Biol. Chem. 2008, 283, 16279-16282. [CrossRef] [PubMed]

28. Kalluri, R. Basement membranes: Structure; assembly and role in tumour angiogenesis. Nat. Rev. Cancer. 2003, 3, 422-433. [CrossRef] [PubMed]

29. Bondar, B.; Fuchs, S.; Motta, A.; Migliaresi, C.; Kirkpatrick, C.J. Functionality of endothelial cells on silk fibroin nets: Comparative study of micro- and nanometric fibre size. Biomaterials 2008, 29, 561-572. [CrossRef] [PubMed]

30. Chen, M.; Patra, P.K.; Warner, S.B.; Bhowmick, S. Role of fiber diameter in adhesion and proliferation of NIH 3 T3 fibroblast on electrospun polycaprolactone scaffolds. Tissue Eng. 2007, 13, 579-587. [CrossRef] [PubMed]

31. Badami, A.S.; Kreke, M.R.; Thompson, M.S.; Riffle, J.S.; Goldstein, A.S. Effect of fiber diameter on spreading, proliferation, and differentiation of osteoblastic cells on electrospun poly(lactic acid) substrates. Biomaterials 2006, 27, 596-606. [CrossRef] [PubMed]

32. Rim, N.G.; Shin, C.S.; Shin, H. Current approaches to electrospun nanofibers for tissue engineering. Biomed. Mater. 2013, 8, 014102. [CrossRef] [PubMed]

33. Zhang, X.; Tsukada, M.; Morikawa, H.; Aojima, K.; Zhang, G.; Miura, M. Production of silk sericin/silk fibroin blend nanofibers. Nanoscale Res. Lett. 2011, 6, 510. [CrossRef] [PubMed]

34. Muylaert, D.E.; van Almen, G.C.; Talacua, H.; Fledderus, J.O.; Kluin, J.; Hendrikse, S.I.; van Dongen, J.L.; Sijbesma, E.; Bosman, A.W.; Mes, T.; et al. Early in-situ cellularization of a supramolecular vascular graft is modified by synthetic stromal cell-derived factor- $1 \alpha$ derived peptides. Biomaterials 2016, 76, 187-195. [CrossRef] [PubMed] 
35. Thomas, L.V.; Lekshmi, V.; Nair, P.D. Tissue engineered vascular grafts—Preclinical aspects. Int. J. Cardiol. 2013, 167, 1091-1100. [CrossRef] [PubMed]

36. Swartz, D.D.; Andreadis, S.T. Animal models for vascular tissue-engineering. Curr. Opin. Biotechnol. 2013, 24, 916-925. [CrossRef] [PubMed]

37. Ahmed, M.; Hamilton, G.; Seifalian, A.M. The performance of a small-calibre graft for vascular reconstructions in a senescent sheep model. Biomaterials 2014, 35, 9033-9040. [CrossRef] [PubMed]

38. Causa, F.; Battista, E.; Della Moglie, R.; Guarnieri, D.; Iannone, M.; Netti, P.A. Surface investigation on biomimetic materials to control cell adhesion: The case of RGD conjugation on PCL. Langmuir 2010, 26, 9875-9884. [CrossRef] [PubMed]

39. Zhang, H.; Hollister, S. Comparison of bone marrow stromal cell behaviors on poly(caprolactone) with or without surface modification: Studies on cell adhesion; survival and proliferation. J. Biomater. Sci. Polym. Ed. 2009, 20, 1975-1993. [CrossRef] [PubMed]

40. Gabriel, M.; van Nieuw Amerongen, G.P.; van Hinsbergh, V.W.; Amerongen, A.V.; Zentner, A. Direct grafting of RGD-motif-containing peptide on the surface of polycaprolactone films. J. Biomater. Sci. Polym. Ed. 2006, 17, 567-577. [CrossRef] [PubMed]

41. Sedaghati, T.; Jell, G.; Seifalian, A. Investigation of Schwann cell behaviour on RGD-functionalised bioabsorbable nanocomposite for peripheral nerve regeneration. New Biotechnol. 2014, 31, 203-213. [CrossRef] [PubMed]

(C) 2016 by the authors; licensee MDPI, Basel, Switzerland. This article is an open access article distributed under the terms and conditions of the Creative Commons Attribution (CC-BY) license (http://creativecommons.org/licenses/by/4.0/). 